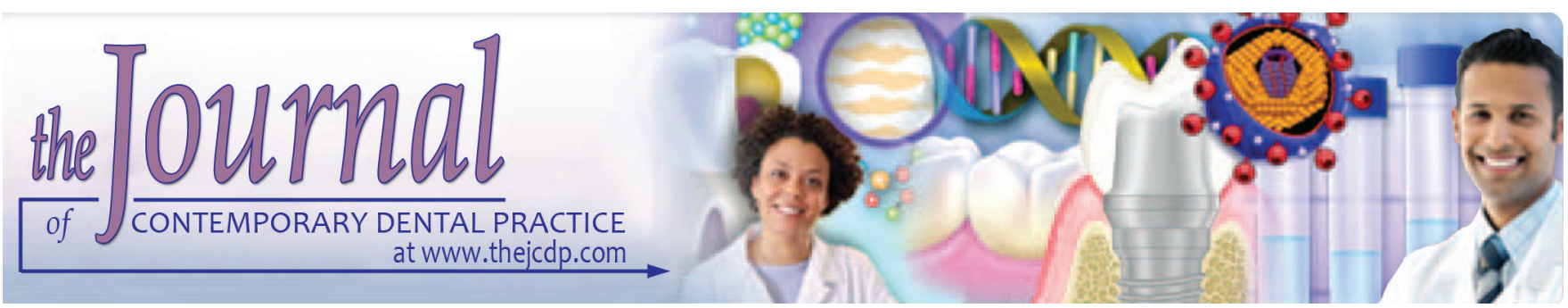

\title{
Effect of Intraoral Aging on Debris Accumulation and Friction of First Molar Tubes
}

\author{
${ }^{1}$ Edmond Chaptini, ${ }^{2}$ Elie Khoury, ${ }^{3}$ Vittorio Cacciafesta, ${ }^{4}$ Nada Naaman
}

\begin{abstract}
Aim: The aim of this article was to evaluate the impact of intraoral aging and site specificity on debris accumulation and friction in molar tubes after intraoral use.

Materials and methods: A total of 80 intraorally used first molar convertible tubes were provided by 20 orthodontic adolescent patients after 6 months of treatment. The specimens were divided into eight groups ( $n=10)$ according to the mouth quadrant and the type of examination [four groups of ten tubes for scanning electron microscope (SEM) and four groups of ten tubes for friction test]. Scanning electron microscope examination was performed after opening the convertible caps and friction test was executed using a $0.01{ }^{\prime \prime} \times 0.025^{\prime \prime}$ stainless steel wire, which was inserted in the tubes belonging to each group. The Mann-Whitney test, analysis of variance (ANOVA), and Bonferroni tests were performed for statistical analysis at 0.01 level of significance.
\end{abstract}

Results: There was a significant increase in the amount of debris and frictional force after 6 months of intraoral exposure $(p<0.0001)$. Debris scores were higher $(10 \%$ increase) on the upper tubes when compared with the lower ones, with no statistical difference. Mean frictional force ranged from 0.22 to $0.26 \mathrm{~N}$ according to the mouth quadrant, but the difference between groups was also not significant.

Conclusion: After 6 months of intraoral exposure, there was a significant increase in the amount of debris in the first molar tube slots, leading to significantly higher frictional forces during sliding mechanics. The influence of site specificity on the amount of debris and on frictional forces of the first molar tubes could not be demonstrated.

Clinical significance: Molar tubes should be cleaned, before and during sliding mechanics, in order to minimize friction.

\footnotetext{
${ }^{1,2}$ Department of Orthodontics, Faculty of Dental Medicine Saint-Joseph University of Beirut, Beirut, Lebanon

${ }^{3}$ Private Practice of Lingual Orthodontics, Milano, Italy

${ }^{4}$ Faculty of Dental Medicine, Saint-Joseph University of Beirut, Beirut Lebanon

Corresponding Author: Elie Khoury, Department of Orthodontics Faculty of Dental Medicine, Saint-Joseph University, Beirut Lebanon, e-mail: elie.khoury@usj.edu.lb
}

Keywords: Debris, Friction, Intraoral aging, Molar tubes.

How to cite this article: Chaptini E, Khoury E, Cacciafesta V, Naaman N. Effect of Intraoral Aging on Debris Accumulation and Friction of First Molar Tubes. J Contemp Dent Pract 2016;17(11):914-919.

Source of support: Nil

Conflict of interest: None

\section{INTRODUCTION}

Friction is the resistance to movement when a wire slides in a bracket slot. ${ }^{1}$ Overcoming friction has been one of the main interests in orthodontic research and inspired a lot of manufacturers in the development of new orthodontic materials and products. ${ }^{2}$

Several in vitro studies have investigated friction when combining as-received wires and brackets, with a variation of the alloy used, ${ }^{3}$ the bracket type, ${ }^{4}$ the wire and bracket dimension, ${ }^{5}$ the wire and bracket angulation, ${ }^{3,6}$ and the ligation type between the bracket and the wire., ${ }^{7,8}$ Other studies investigated friction in the presence of fluids tentatively to simulate the intraoral environment. Some of these studies showed that friction decreases in the presence of saliva, ${ }^{9}$ while others showed that saliva may not act as a lubricant. ${ }^{10,11}$

Intraorally used wires were recently investigated in order to elucidate the effect of biological factors, such as corrosion and plaque, on sliding mechanics. ${ }^{12}$ Nitinol wires and stainless steel wires showed a significantly increased amount of debris and roughness after intraoral aging, ${ }^{13}$ but only stainless steel wires showed a significant increase in friction due to these factors. ${ }^{12}$ One recent article compared the effect of intraoral aging on conventional and self-ligating bracket slots and found that both of them showed a significant increase in the frictional force during sliding mechanics. ${ }^{14}$

Sliding mechanics in preadjusted appliances is the mostly used method for moving a tooth or a group of 
teeth. The efficiency of the system is affected by increased frictional forces, which can reach up to $50 \%$ of the force applied ${ }^{15}$ and can delay the treatment because of little or no tooth movement. The majority of published studies on friction simulated the movement of a bracket sliding along a wire, assuming that it reproduces the clinical reality of a canine retraction mechanics on a continuous wire or sliding mechanics of a wire in the premolar bracket. ${ }^{6,11,12,14}$ In en masse closure using sliding mechanics, the retraction of six anterior teeth occurs when the archwire slides along the bracket of the second premolar and the tubes of the first and second molars, which relates the importance of studying the behavior of molar tube slots in sliding mechanics.

The aim of this study is to evaluate the impact of intraoral aging and site specificity on debris accumulation and friction in molar tubes after intraoral use.

\section{MATERIALS AND METHODS}

After the approval of the Research Ethics Board, the calculation of the sample size was done based on a pilot study on six pairs of as-received and used tubes, in order to observe a difference of $0.1 \mathrm{~N}$ with a standard deviation (SD) of $0.063 \mathrm{~N}$, with a power of $90 \%$ and an alpha level of 0.05 . The calculated sample size was $n=9$ for both asreceived and clinically exposed tubes.

Twenty as-received convertible triple tubes (3M Unitek, , Monrovia, CA, USA; www.3Munitek.com), with MBT prescription (upper tubes: Width $4.3 \mathrm{~mm}$, torque $-14^{\circ}$, distal offset $-10^{\circ}$, auxiliary torque $0^{\circ}$; lower tubes: Width $4.3 \mathrm{~mm}$, torque $-20^{\circ}$, distal offset $0^{\circ}$, auxiliary torque $0^{\circ}$ ), formed the control group. Ten tubes were opened in order to be examined by the scanning electron microscope (SEM), and ten tubes were designated to the friction test. In order to preserve the bracket slot from scratching by the use of a convertible cap-removing plier, the temporary cap representing the fourth wall of the tube was sheared off by inserting a 0.014 " stainless steel wire into the slot and tying together the distal and mesial ends until the temporary cap was distorted and removed. The as-received tubes were named according to the test type (SEM as-received group: SEMAR; friction as-received group: FRAR).

A total of 80 intraorally used first molar convertible triple tubes (3M Unitek, Monrovia, CA, USA; www.3Munitek.com), with the same MBT prescription, were provided by 20 orthodontic adolescent patients ( 8 girls and 12 boys, aged between 12 and 19 years, with a mean age of 14.9 years), who were scheduled to receive orthodontic treatment. At the start of treatment, each patient was equipped with bands on upper and lower molars and Gemini MBT prescription brackets (3M Unitek, Monrovia, CA, USA; www.3Munitek.com) on the remaining teeth. These patients received a routine checkup, cleaning and hygiene instructions 10 days before treatment start, and at the end of the bonding session by the same operator. The 20 patients were followed up for the first 6 months, during the leveling and alignment phase, until each of them received $0.019^{\prime \prime} \times 0.025^{\prime \prime}$ stainless steel wires usually used for sliding mechanics. At the end of the alignment phase, the four first molar bands were removed from each patient's mouth by cutting them with a transmetal bur (E0153, $19 \mathrm{~mm}$, ISO 012, Dentsply Maillefer, Ballaigues, Switzerland; www.dentsplymaillefer.com), in order to prevent deformation of the tube, which could occur with the use of a band-removing plier. The patients received new tubes and continued the treatment normally.

A total of 80 used first molar tubes were separated from the bands using a sharp cutter, in order to be studied in SEM and tested for friction resistance. They were divided into eight groups of ten tubes each, and named according to the test type and mouth quadrant: SEM upper right group: SEMUR, SEM upper left group: SEMUL, SEM lower right group: SEMLR, SEM lower left group: SEMLL, friction upper right group: FRUR, friction upper left group: FRUL, friction lower right group: FRLR, and friction lower left group: FRLL.

\section{Scanning Electron Microscope Analysis}

For the SEM examination, each tube was fixed on a carbon tab and oriented for observation of the deepest wall of the slot using a SEM (FEI Quanta 600 FEG, Hilsboro, USA; www.fei.com) under the following conditions: $5.1 \times 10^{-6} \mathrm{~Pa}$ vacuum; $10 \mathrm{kV}$ accelerating voltage; $100 \mathrm{~mA}$ beam current; ultrathin sampling window on the SiLi Pioneer detector; $100 \mathrm{~s}$ acquisition time; 10 to $20 \%$ dead time.

For each tube, images were obtained by secondary electrons with $150 \times$ magnification. Five images with $150 \times$ magnification were necessary to cover the whole slot length. Images were captured in the same direction from mesial to distal. Debris quantification was done by one operator according to a published method in endodontics, ${ }^{16}$ and the following scores were attributed to the images: $0=$ total absence of debris, 1 = debris covering one-fourth of the image, 2 = debris covering one-fourth to three-fourths of the image, 3 = debris covering more than three-fourths of the image (Figs 1A and B). Two blinded readings with 10 days interval were done for error analysis, and Spearman's correlation test at $\mathrm{p}<0.05$ was performed to evaluate the reliability of the debris quantification method.

\section{Friction Test}

The friction test was performed by fixing the tubes on acrylic plates (area $=4 \times 6 \mathrm{~cm}$ and thickness $5 \mathrm{~mm}$ ) based 


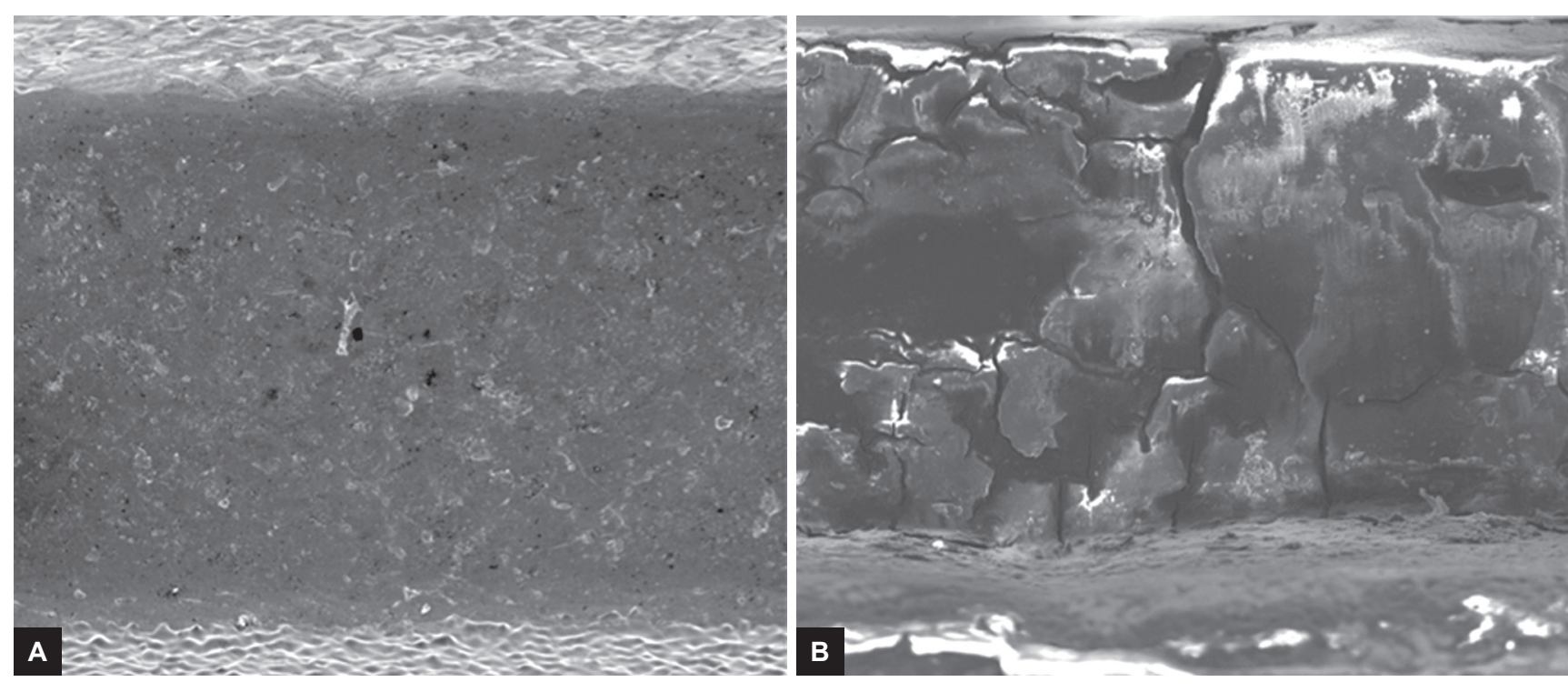

Figs 1A and B: Scanning electron microscope images at 150× magnification: (A) As-received tube with debris score 0; and $(B)$ clinically exposed tube with debris score 3

on a modification of a methodology published previously. ${ }^{12}$ All tubes belonging to the same quadrant were coupled one by one with the same reference tube (not belonging to the sample) in order to align them on two adjacent acrylic plates. The alignment was done using a $0.022^{\prime \prime} \times 0.028^{\prime \prime}$ stainless steel wire template inserted in the accessory tube in order to keep the primary slot untouched.

Before the friction test, a $0.019^{\prime \prime} \times 0.025^{\prime \prime}$ stainless steel straight wire with an omega loop stop was inserted in the primary slot of the reference tube and tied to it using a metallic ligature. The two plates were then assembled by engaging the wire in the tube to be tested.

The plates were fixed in the universal testing machine (YLE Germany) with a load cell of $22 \mathrm{~N}$. The plate containing the reference tube was set at the upper grip, while the plate holding the tube to be tested was fixed on the lower grip (Fig. 2). The friction test was done in compression, the wire slided in the slot of the tube from mesial to distal (imitating the clinical situation) at the speed of $1 \mathrm{~mm}$ per minute for a $5 \mathrm{~mm}$ distance. The wire attached to the reference tube was cleaned with alcohol (96\%) after each test. The kinetic force was registered during the whole movement.

All the tests were performed following the same procedures. Ten as-received tubes (FRAR group) were tested in friction and represented the control group. A total of 40 used tubes (FRUR, FRUL, FRLR, FRLL groups) were evaluated in friction test after 6 months of intraoral exposure.

\section{RESULTS}

Statistical analysis was performed using the Statistical Package for the Social Sciences (SPSS) version 20 software program (Inc., Chicago, Illinois, USA; www.spss.com).

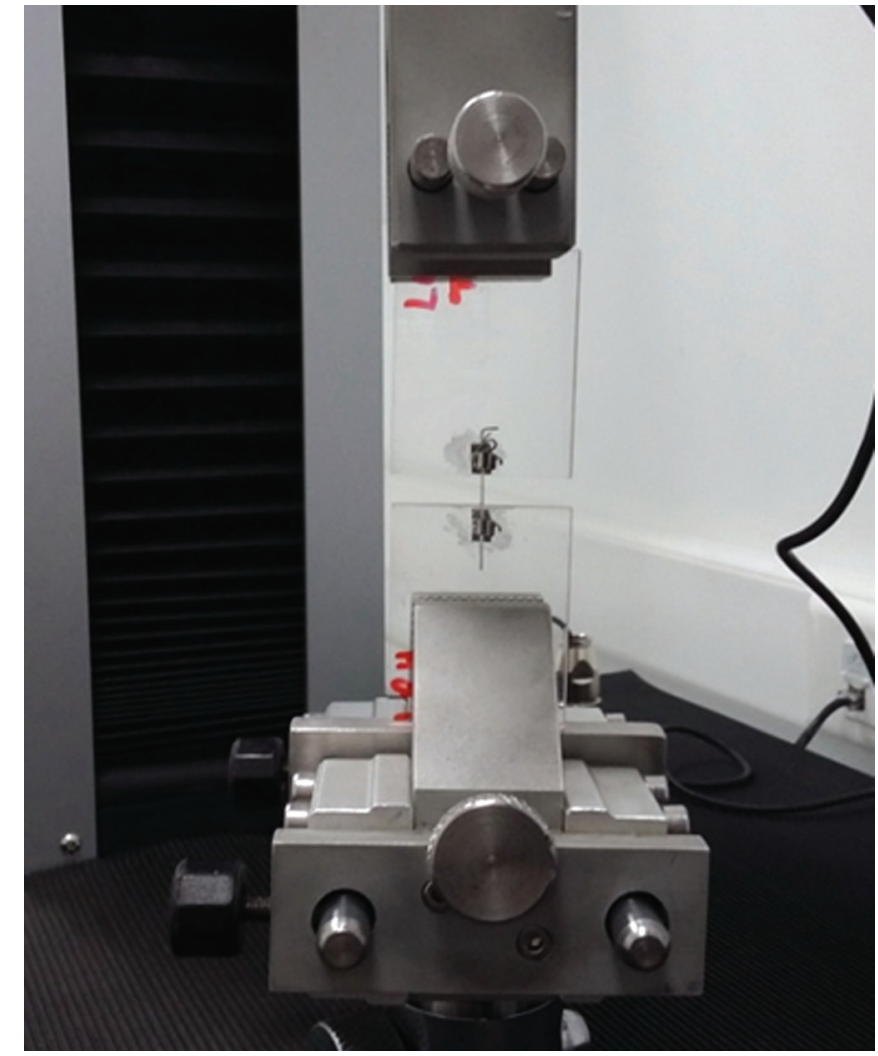

Fig. 2: Universal testing machine set-up for friction test

For the SEM images, the reproducibility of the scoring was tested using the Spearman correlation analysis and showed a high correlation between the scores registered by two operators $(p<0.0001, r=0.96)$. The descriptive analysis of the sample is represented in Table 1. The score "zero" was attributed to all as-received tubes, while the tubes that were maintained for 6 months in the oral environment showed a significant increase in the debris scores. The calculated median score for the four groups 
Effect of Intraoral Aging on Debris Accumulation and Friction of First Molar Tubes

Table 1: Descriptive statistics of SEM images and comparison between as-received and clinically exposed groups

\begin{tabular}{|c|c|c|c|c|c|}
\hline \multirow[b]{2}{*}{ SEM scores } & \multirow{2}{*}{$\frac{\text { As-received group }}{\text { SEMAR }}$} & \multicolumn{4}{|c|}{ Clinically exposed group } \\
\hline & & SEMUR & SEMUL & SEMLR & SEMLL \\
\hline 0 & 10 & 0 & 0 & 0 & 0 \\
\hline 1 & 0 & 3 & 2 & 4 & 3 \\
\hline 2 & 0 & 7 & 7 & 6 & 6 \\
\hline 3 & 0 & 0 & 1 & 0 & 1 \\
\hline Median & 0 & 2 & 2 & 2 & 2 \\
\hline $\begin{array}{l}\text { Comparison between as-received } \\
\text { and clinically exposed groups }\end{array}$ & $p=1.000$ & $p<0.001$ & $p<0.001$ & $p<0.001$ & $p<0.001$ \\
\hline
\end{tabular}

Table 2: Descriptive statistics of the friction test: Mean frictional values in Newton for as-received group, FRAR $(n=10)$, and each of the clinically exposed groups $(n=10)$ representing the four intraoral quadrants

\begin{tabular}{lllll}
\hline & Mean & SD & Minimum & Maximum \\
\hline FRAR & 0.09 & 0.03 & 0.048 & 0.146 \\
FRUR & 0.24 & 0.05 & 0.164 & 0.324 \\
FRUL & 0.26 & 0.06 & 0.171 & 0.369 \\
FRLR & 0.22 & 0.05 & 0.151 & 0.303 \\
FRLL & 0.24 & 0.06 & 0.161 & 0.339 \\
\hline
\end{tabular}

after intraoral aging was 2 at $150 \times$ magnification. For the lower right and lower left tubes, $60 \%$ of the sample was found to have a score of 2 after intraoral aging (debris covering one-fourth to three-fourths of the image), while the same score 2 was found in $70 \%$ of the upper right and left tubes. The Mann-Whitney test was performed to compare the variables. The difference was significant when the four groups representing the four mouth quadrants after intraoral aging were compared with asreceived group $(\mathrm{p}<0.001)$, while no statistical difference was found when comparing the four clinically exposed groups together (Table 1).

For the friction test, the normal distribution of the groups was verified using the Kolmogorov-Smirnov test. The descriptive analysis of the mean frictional values for the five groups is represented in Table 2. The analysis of variance (ANOVA) test (Table 3) and the Bonferroni multicomparison test (Table 4) were used to evaluate

Table 4: Bonferroni multiple comparison test for friction between post hoc groups

\begin{tabular}{lcll}
\hline & $\begin{array}{l}\text { Mean } \\
\text { difference }\end{array}$ & $\begin{array}{l}\text { Standard } \\
\text { error }\end{array}$ & $p$-value \\
\hline FRAR vs FRUR & -0.156 & 0.024 & $0.00000075^{*}$ \\
FRAR vs FRUL & -0.170 & 0.024 & $0.000000096^{*}$ \\
FRAR vs FRLR & -0.136 & 0.024 & $0.0000124^{*}$ \\
FRLR vs FRLL & -0.152 & 0.024 & $0.0000012^{*}$ \\
FRUR vs FRUL & -0.146 & 0.024 & 1.000 \\
FRUR vs FRLR & 0.02 & 0.024 & 1.000 \\
FRUR vs FRLL & 0.18 & 0.024 & 1.000 \\
FRUL vs FRLR & 0.034 & 0.024 & 1.000 \\
FRUL vs FRLL & 0.018 & 0.024 & 1.000 \\
FRLR vs FRLL & 0.016 & 0.024 & 1.000 \\
\hline
\end{tabular}

*Statistically significant at the level of $p<0.01$
Table 3: Analysis of variance for friction test groups

\begin{tabular}{llllrr}
\hline & $\begin{array}{l}\text { Sum of } \\
\text { squares }\end{array}$ & df & $\begin{array}{l}\text { Mean } \\
\text { square }\end{array}$ & $f$-value & $p$-value \\
\hline Between groups & 0.196 & 4 & 0.049 & 16.522 & $<0.0001$ \\
Within groups & 0.133 & 45 & 0.003 & & \\
\hline Total & 0.329 & 49 & & & \\
\hline
\end{tabular}

the difference in friction before and after intraoral aging as well as the difference between the four groups after intraoral aging.

The as-received tubes showed a mean frictional force of $0.09 \mathrm{~N}(\mathrm{SD}=0.03)$, while this force increased significantly in the four groups of tubes after 6 months of intraoral aging, to reach respectively, $0.22 \mathrm{~N}(\mathrm{SD}=0.06)$ for the FRLR group ( $144 \%$ increase); $0.24 \mathrm{~N}(\mathrm{SD}=0.06)$ for the FRLL group ( $166 \%$ increase); $0.24 \mathrm{~N}(\mathrm{SD}=0.05)$ for the FRUR group (166\% increase); $0.26 \mathrm{~N}(\mathrm{SD}=0.06)$ for the FRUL group (188\% increase). The difference between the as-received group's frictional values and each one of the four groups after intraoral aging was statistically significant $(\mathrm{p}<0.001)$.

No statistically significant difference was detected when comparing the four groups after intraoral aging, knowing that group FRUL had the highest friction force $(0.26 \mathrm{~N})$, while group FRLR had the lowest one $(0.22 \mathrm{~N})$.

\section{DISCUSSION}

Intraoral aging of orthodontic material is a determinant factor in the efficiency of orthodontic tooth movement. ${ }^{17}$ The effect of aging on material surface and friction has been the subject of many investigations on Nitinol, stainless steel wires, ${ }^{12,13}$ and to a less extent on brackets. ${ }^{14}$ However, to our knowledge, molar tubes remain unexamined despite the importance of their role in sliding mechanics during en masse retraction. This study aimed to investigate the effect of intraoral aging on frictional forces of first molar tubes in vitro. The tubes were kept in the intraoral environment for 6 months, which corresponds to the alignment period, and were withdrawn and then examined before the beginning of en masse space closure step.

The results of the SEM analysis showed a significant increase in the amount of debris in the tubes after intraoral 
aging. The same results were found in previous studies that investigated conventional, self-ligating brackets, and stainless steel and Nitinol wires. ${ }^{13,14,18,19}$ The comparison of stain scoring between the groups representing the four mouth quadrants after intraoral aging showed an increase of $10 \%$ in score 2 (debris covering one-fourth to threefourths of the image) for the upper left and right groups, but this difference was not statistically significant. Even though it is well known that site specificity could have an impact on the amount of calculus observed on tooth surfaces in different regions of the mouth, ${ }^{20}$ the impact of site specificity on debris accumulation in the tube slots was not proven in this study. A larger sample might be needed for this kind of investigation.

For the friction test, the tubes were aligned through a full size stainless steel wire template inserted in the accessory tube, which kept the primary tube intact for the friction test. Previous studies done on conventional and self-ligating brackets used a full size stainless steel wire inserted in the bracket slot, which could have eliminated a part of the debris and calculus and consequently affected the results. The test was done in compression, and the wire slided from the mesial to the distal part of the tube in order to imitate the en masse movement of sliding as it happens clinically. A straight linear test set-up method was used in this study, while the clinical situation is more complex and involves a three-dimensional (3D) movement of the teeth. Although it is complicated to imitate the dynamic movement that happens in vivo, future investigations should address this issue.

The results of the friction test in the present study showed a mean frictional force of $0.09 \mathrm{~N}$ for as-received tubes. These results are similar to those shown in several studies with a similar set-up done on self-ligating brackets and conventional brackets with metallic ligatures. ${ }^{21,22}$ Frictional forces in tubes after intraoral aging showed a significant increase ranging from 144 to $188 \%$. Even though the upper tubes showed higher values than the lower ones, the statistical difference was not significant, and the role of site specificity in altering frictional resistance of intraorally used first molar tubes could not be demonstrated.

To our knowledge, no similar studies on molar tubes are available for direct comparison of friction test results. However, in a study done on brackets, Araújo et $\mathrm{al}^{14}$ found an increase of $191 \%$ of the frictional force in selfligating brackets coupled with stainless steel wires after only 8 weeks of intraoral aging. These differences can be explained by the bracket design used in their study (open slots that are subject to direct exposure compared with a completely closed tube) and by the test set-up combining a bracket and a wire set, which both were aged for 8 weeks.
The present study investigated first molar tubes with four walls, which were kept in the intraoral environment for 6 months and showed that debris accumulation occurs even in closed tubes after intraoral aging. This phenomenon can be explained by the infiltration of intraoral fluids inside the tube by capillarity and by the mechanical introduction of plaque inside the tube during wire insertion. The extended use of orthodontic appliances over an average treatment time of 24 months may result in more debris accumulation and higher frictional resistance values than those found in this study, and the impact on treatment progress could probably be increased. Patient hygiene and appliance cleaning may play a role in reducing debris on intraoral appliances and improving the efficiency of the treatment in sliding mechanics. Archwire cleaning after intraoral aging ${ }^{23}$ showed a significant decrease in frictional force level, while sodium bicarbonate air abrasive polishing on metallic and ceramic brackets produced more surface roughness and increased friction. ${ }^{24}$ In the present study, the patient was asked to brush his teeth before the adjustment session. Although it is difficult or even impossible to clean the inner space of closed first and second molar tubes, different hygiene measures (toothbrushing or polishing before wire insertion in each session) could be investigated in order to evaluate their impact on debris accumulation.

\section{CONCLUSION}

After 6 months of intraoral exposure, there is a significant increase in the amount of debris in the first molar tube slots leading to significantly higher frictional forces during sliding mechanics.

Site specificity does not seem to have an influence on the amount of debris and frictional forces of the first molar tubes.

\section{CLINICAL SIGNIFICANCE}

Orthodontists should know that debris accumulation in molar tubes can increase friction up to three times during sliding mechanics. Therefore, molar tubes should be cleaned, before and during sliding mechanics, in order to optimize the en masse closure.

\section{REFERENCES}

1. Rossouw PE. Friction: an overview. Semin Orthod 2003 Dec;9(4):218-222.

2. Burrow J. Friction and resistance to sliding in orthodontics: a critical review. Am J Orthod Dentofacial Orthop 2009 Apr;135(4):442-447.

3. Kapila S, Angolkar PV, Duncanson MG, Nanda RS. Evaluation of friction between edgewise stainless steel brackets and orthodontic wires of four alloys. Am J Orthod Dentofacial Orthop 1990 Aug;98(2):117-126. 
4. Cacciafesta V, Sfondrini MF, Scribante A, Klersy C, Auricchio F. Evaluation of friction of conventional and metal-insert ceramic brackets in various bracket-archwire combinations. Am J Orthod Dentofacial Orthop 2003 Apr;123(4): 403-409.

5. Kim TK, Kim KD, Baek SH. Comparison of frictional forces during the initial leveling stage in various combinations of self-ligation brackets and archwires with custom-designed typodont system. Am J Orthod Dentofacial Orthop 2008 Jan;133(1):15-24.

6. Frank CA, Nikolai RJ. A comparative study of frictional resistances between orthodontic racket and arch wire. Am J Orthod Dentofacial Orthop 1980 Dec;78(6):593-609.

7. Thorstenson GA, Kusy RP. Resistance to sliding of selfligating brackets versus conventional stainless steel twin brackets with second-order angulation in the dry and wet (saliva) states. Am J Orthod Dentofacial Orthop 2001 Oct;120(4): 361-370.

8. Kusy RP, Whitley JQ. Coefficients of friction for arch wires in stainless steel and polycrystalline alumina brackets slots. I. The dry states. Am J Orthod Dentofacial Orthop 1990 Oct;98(4):300-312.

9. Al-Khatib S, Berradja A, Celis J-P, Williems G. In vitro friction of stainless steel arch wire-bracket combination in air and different aqueous solutions. Orthod Craniofacial Res 2005 May;8(2):96-105.

10. Mendes K, Rossouw PE. Friction: validation of manufacturer's claim. Semin Orthod 2003 Dec;9(4):236-250.

11. Smith DV, Rossouw PE, Watson P. Quantified simulation of canine retraction: evaluation of frictional resistance. Semin Orthod 2003 Dec;9(4):262-280.

12. Marques ISV, Araujo AM, Gurgel JA, Normando D. Debris, roughness and friction of stainless steel archwires following clinical use. Angle Orthod 2010 May;80(3):521-527.

13. Wichelhaus A, Geserick M, Hibst R, Sander FG. The effect of surface treatment and clinical use on friction in NiTi orthodontic wires. Dent Mater 2005 Oct;21(10):938-945.
14. Araújo RC, Bichara LM, Araujo AM, Normando D. Debris and friction of self-ligating and conventional orthodontic brackets after clinical use. Angle Orthod 2015 Jul;85(4):673-677.

15. Drescher D, Bourauel C, Schumacher H. Frictional forces between bracket and arch wire. Am J Orthod Dentofacial Orthop 1989 Nov;96(5):397-404.

16. Van Eldik DA, Zilm PS, Rogers AH, Marin PD. A SEM evaluation of debris removal from endodontic files after cleaning and steam sterilization procedures. Aust Dent J 2004 Sep;49(3):128-135.

17. Eliades $\mathrm{T}$, Bourauel C. Intraoral aging of orthodontic materials: the picture we miss and its clinical relevance. Am J Orthod Dentofacial Orthop 2005 Apr;127(4):403-412.

18. Eliades T, Eliades G, Athanasiou AE, Bradley TG. Surface characterization of retrieved NiTi orthodontic archwires. Eur J Orthod 2000 Jun;22(3):317-326.

19. Daems J, Celis J, Willems G. Morphological characterization of as-received and in vivo orthodontic stainless steel archwires. Eur J Orthod 2009 Jun;31(3):260-265.

20. Dawes $C$. Why does supragingival calculus form preferentially on the lingual surface of the 6 lower anterior teeth? J Can Dent Assoc 2006 Dec;72(10):923-926.

21. Thorstenson GA, Kusy RP. Comparison of resistance to sliding between different self-ligating brackets with secondorder angulation in the dry and saliva states. Am J Orthod Dentofacial Orthop 2002 May;121(5):472-482.

22. Ehsani S, Mandich MA, El-Bialy TH, Flores-Mir C. Frictional resistance in self-ligating orthodontic brackets and conventionally ligated brackets. Angle Orthod 2009 May;79(3):592-601.

23. Normando D, De Araujo AM, Marques ISV, Dias CGBT, Miguel JAM. Archwire cleaning after intraoral aging: the effects on debris, roughness, and friction. Eur J Orthod 2013 Apr;35(2):223-229.

24. Parmagnani EA, Basting RT. Effect of sodium bicarbonate air abrasive polishing on attrition and surface micromorphology of ceramic and stainless steel brackets. Angle Orthod 2012 Mar;82(2):351-362. 